\title{
Development and Exploration of Cloud-based Three-dimensional Digital Resource Sharing Courses
}

\author{
Weifeng Zhu \\ Guangdong Engineering Polytechnic, Guangzhou, \\ Guangdong 510520
}

\author{
Jun Tian \\ Foshan Polytechnic, Foshan, Guangdong 528137
}

\begin{abstract}
With the maturity of cloud technology and the advance of national education informatization process, the construction of professional courses has gradually focused on cloud-based three-dimensional digital resources sharing, thus breaking the shackles of traditional teaching mechanism. The focus of the development of three-dimensional digital resources sharing courses has shifted to the development of cloud-based three-dimensional digital resources of the teaching materials of professional courses and synchronous innovation of classroom teaching mode, the construction of three-dimensional digital resources sharing has developed into a gradual process in which the construction of teaching materials of professional courses, become a professional and professional skills training relying on each other.
\end{abstract}

Keywords-Three-dimensional digital resources; Construction of teaching materials of professional courses; Cloud technology.

\section{CONSTRUCTION StATUS OF THREE-DimENSIONAL Digital RESOURCE SHARING COURSES}

In recent years, with the rapid development of cloud technology and information technology education applications, three-dimensional digital resources for the field of education have been in the ascendant. In 2001, China began the construction of excellent courses, and it has been promoted throughout China in 2003. In 2010, construction of National Excellent Courses had been successfully completed. The construction of Excellent Course is an important part of the "Teaching Quality and Teaching Reform Projects in higher education" launched by Ministry of Education, and is an important measure to deepen the teaching reform, to promote the education modernization with education informatization developed by Ministry of Education, which has important significance to improve the teaching and the quality of talents cultivation in the institutions of higher education.

The " Quality Project" - Construction of Excellent Courses launched in 2003 was regarded as the excellent courses with distinctive and excellent teaching standards, but due to the limitations of video technology, network bandwidth and other conditions, a limited number of video courses were offered, and the quality was not high, the design was not reasonable. Even after years of development, the quality of the excellent courses developed is still uneven, especially in the lagged course technology; although the time of course development is long, its life cycle is short, Especially the educational video resources in the traditional communication carriers did not give full play to the communication advantages of television media, they were once documented; but after the educational video resources took advantages of new media technology, three-dimensional digital resources sharing courses have received more and more attention from the educational field. Currently, it has involved the excellent courses, open classes of video courses, educational video network, portals, micro-lessons, digital $\mathrm{TV}$, mobile video, video resource network of teaching institutions, which have benefitted millions of scholars, promoting the construction climax of three-dimensional digital resources sharing courses once again.

\section{CONSTRUCTION TREND OF THREE-DIMENSIONAL Digital RESOURCES SHARING COURSES}

With the maturity of network technology and the cloud technology, currently, the construction of three-dimensional digital resources sharing courses has further been related to development of excellent open courses, which is mainly completed through the network courses, the Phoenix micro lessons, MOOC and other forms, and it is widely used in the application of National Video Open Classes, the combination of scientific and cultural qualities, professional introduction, professional development and employment guidance and occupation skills contest. As shown in Figure 1, the construction of three-dimensional digital resources sharing courses has been a hot issue.

With the gradual popularization of MOOC courses, the comprehensive changes of teaching methods in universities and colleges, and preparation and adjustment of degrees and credits system, the higher demand of three-dimensional digital resources sharing courses for the video courses supported by modern education technology based on current network technology and the cloud technology is to be solved. Gradually, new resources centered on courses has been constructed, and, existing resources have been integrated and gathered, especially colleges and universities and the press all over the country are vigorously carrying out various kinds of electronic version of the teaching materials or the network teaching resources which are matched with the traditional text materials, so as to develop and construct threedimensional teaching materials. 


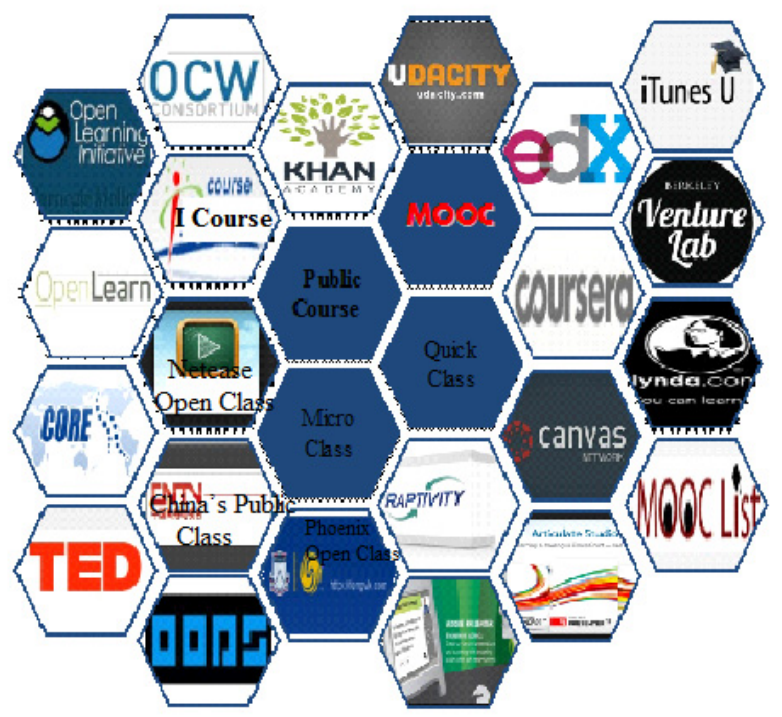

Figure 1. Hot spots in the construction of three-dimensional digital resources sharing courses

III. TeChNiCAL Support ThreE-Dimensional Digital RESOURCES SHARING COURSES CONSTRUCTION

Throughout the course of its development, the evolution of network courses can be seen from the management platform, as shown in Figure 2.

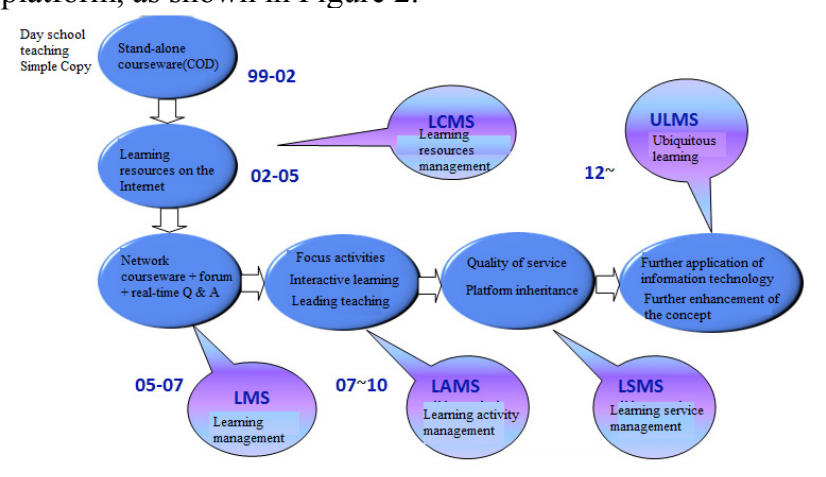

Figure 2. Evolution of network courses from the perspective of the development of the management platform

The focus and difficulty of three-dimensional digital resources sharing courses is the video recording, but the current micro courses generally have been promoted, in this paper, micro courses are taken as an example to introduce the production process. As shown in Figure 3.

\section{A. Production Process of Micro Class}

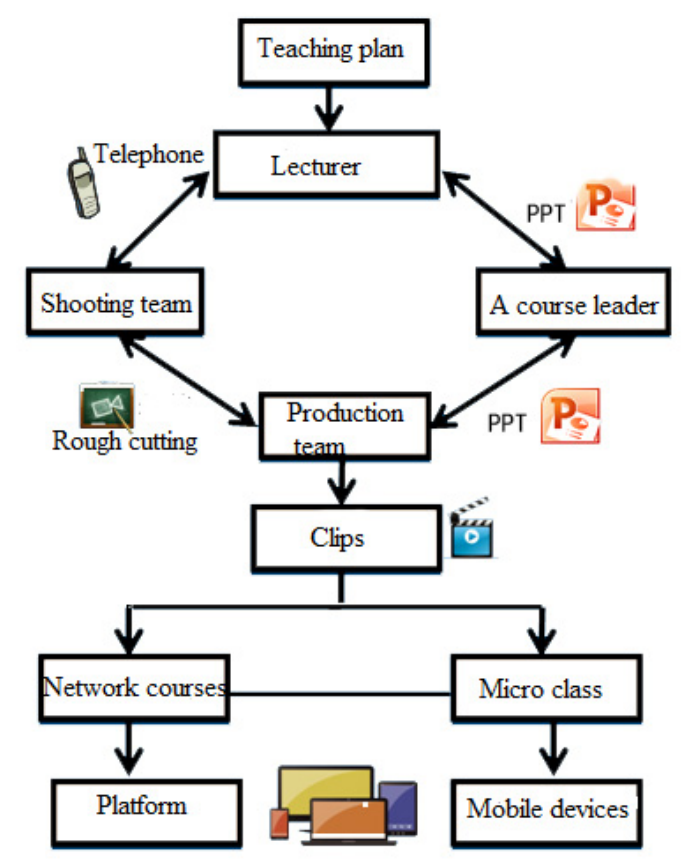

Figure 3. Production Process of Micro Classes

Production approaches of micro class have two kinds of original development and processing modification, the original development approach mainly includes: micro class made through video camera shooting tools, micro class made through screen recording software, micro class made through software tools synthesis, and micro class made through mixed type, in which, the micro class through video camera shooting tools is produced by DV cameras, smart phones, web cameras, digital cameras, etc which have the external devices with function of photography video, which recorded and filmed down the real-life situations of teachers' teaching and explained the content, operation and demonstration and the whole process of learning.

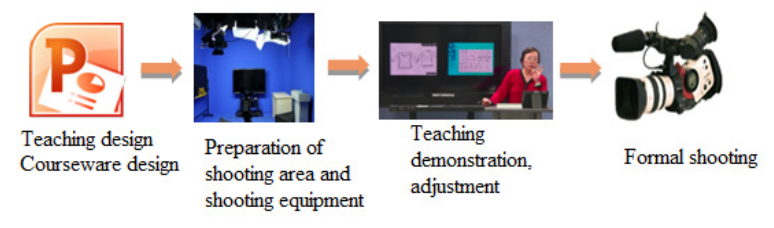

Figure 4. Production of Micro Class with Shooting Tools

Micro class with shooting tools can be divided into professional level and amateur level. Fig. 5 is the micro professional class made through video camera shooting tools; FIG. 6 is the micro professional micro class. 


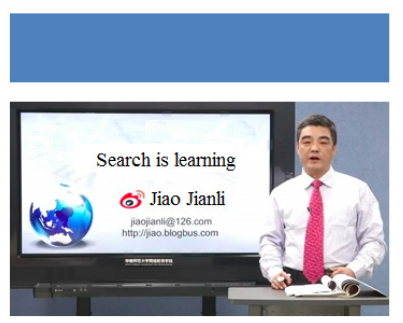

TV whiteboard touch all-in-one PC
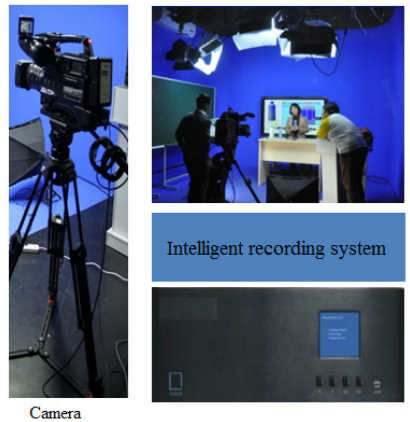

Figure 5. Micro Professional Class Made through Video Camera Shooting Tools

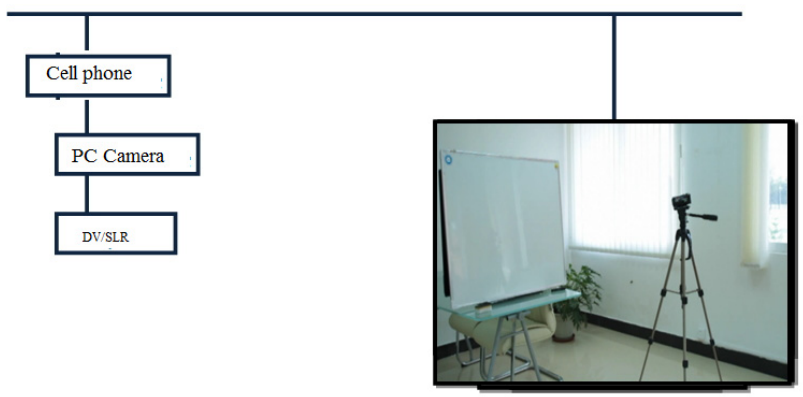

Figure 6. Micro Professional Micro Class

The micro class made through screen recording software recorded the real-life situations of teachers' teaching by explaining, analyzing and demonstration; or by the video recording of interactive white board, one machine and other digital media, simultaneously recording the videos of classroom teaching. As shown in Figure 7.

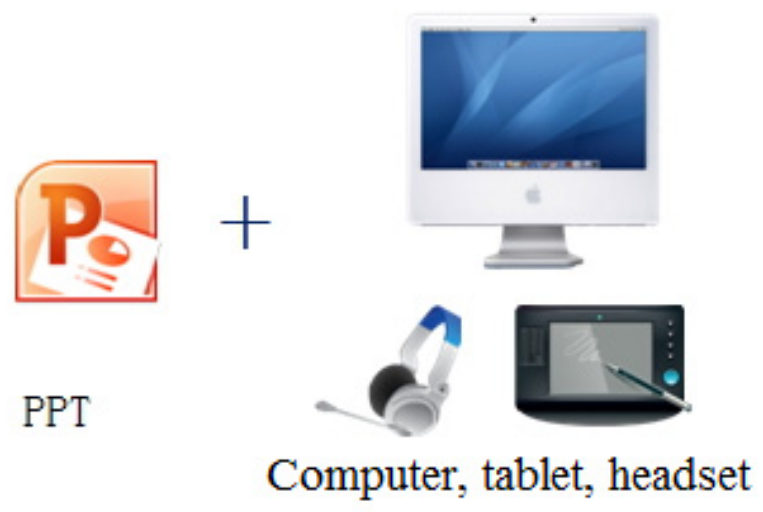

Figure 7. Screen Recording Micro Class

Micro class made through software synthesis adopted images, animation or video editing software (such as Flash, Premiere, PPT, Ulead Video Studio, Movie Maker, electronic photo album, Mtxiuxiu and other animation, audio and video software), through the script design of micro class, synthesis technology, the teaching video clips are produced.
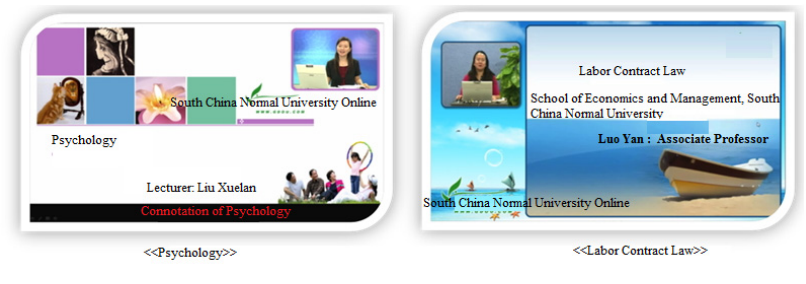

Figure 8. Micro Class Made Through Screen Recording Software

Micro class made from the mixed production uses a variety of video production methods mentioned above (such as shooting, recording screen, software synthesis, etc.) after some post-editing, micro classes are processed and synthesized. The quality of micro video produced by this approach is relatively higher (appreciation and learning, etc.) will be relatively higher.

\section{B. Construction Standards}

\section{a) Source materials}

(1) The Chinese character in this study mainly used the GB code for unified coding and storage, English letters and symbols used ASCII for encoding and storage, text color was coordinated with a unified style; and simplified characters and common fonts were used, such as Song typeface, Regular Script and Black Body and so on.

(2) the resolution of image resources is not less than 800 * 600, the image quality is not less than 16bit, common format is JPG, PNG, GIF and so on.

(3) The sampling frequency of sound materials digitized audio is not less than $44 \mathrm{KHZ}$, the number of channels is the dual channel ( stereo ), the streaming media formats (MP3, $\mathrm{AAC}$, etc. ) are adopted, and it is required to be played clearly and smoothly.

(4) The resolution of video clips is not less than ( $640 *$ 360 ), the frame rate is not less than 25 frames / sec, bit stream is not less than $1 \mathrm{Mb} / \mathrm{s}$, the audio and video in the materials are in sync with a smooth playback, good clarity, there is no partial light or dark scene.

(5) Animation materials require a modest screen size, it is better to use the 16:9 resolution, which can generally meet the requirements to play 24-30 frames / sec, the sound is clear and smooth in animation; which uses the common formats such as WAV, MP3, etc.; the subtitles is clear, the style of fonts is not more than three kinds, such as SWF or MOV format.

b) Standards Micro- class Products

(1) Standards of video streaming: video bit rate is not less than $5 \mathrm{Mbps}$; with a progressive scan; frame rate is not less than $25 \mathrm{fps}$; the resolution is not less than $720 * 576(4: 3)$ or $1024 * 576(16: 9)$.

In which, the standards micro- class are as follows: Resolution is $640 * 360$, stream is typically $200 \mathrm{Kbps}$. 
(2) The standards of audio stream are as follows: MP3 or AAC can be used to code; dual channels; audio bit rate is not less than $256 \mathrm{Kbps}$; the audio sample is not less than $44100 \mathrm{~Hz}$.

If the HD is derived, then derived standards of HD video (taking Adobe Premiere CS6 as an example) are as follows: 1.the video output format is H.264, uses the highest rendering quality; 2 . the basic video settings: the resolution is $1920 * 1080$; the frame rate is $25 ; 3$. the audio format is AAC; sampling rate is $48000 \mathrm{~Hz}$; bit rate is 320 ; 4 . the multiplexer is set to be MP4; flow compatibility is set to be standardized.

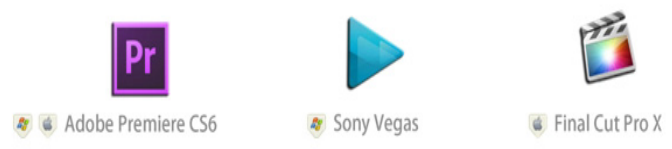

C. Release of Micro Class
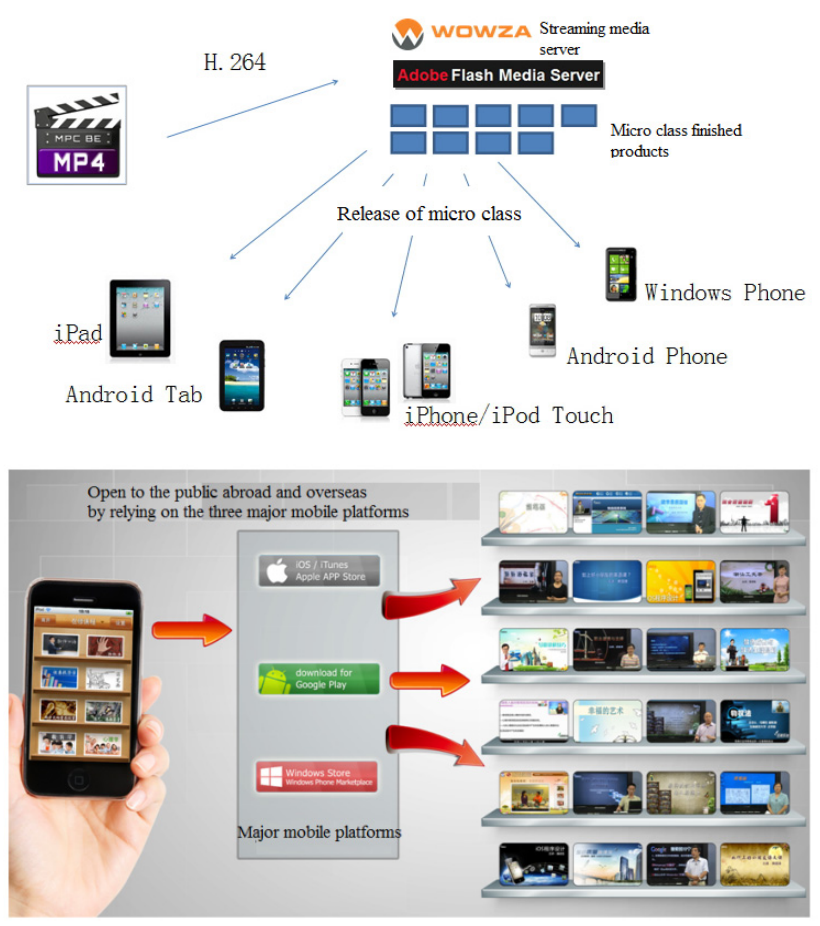

\section{OUTLOOK OF THREE-DIMENSIONAL DigITAL RESOURCES SHARING COURSES CONSTRUCTION}

Cloud-based Internet higher education cross-border trade will produce a subversive influence on the reform of higher education; the video resources involved in the project are from single ones to comprehensive one, which will gradually be spread to the teaching contests in higher education micro class, application, response and conclusion of the projects, such as the school-enterprise cooperation innovation projects.

From the perspective of content, the three-dimensional digital resources sharing courses include the threedimensional teaching materials and video resources. In which, the three-dimensional teaching materials include the main teaching materials, teacher reference books, reference books, test database; from the perspective, the threedimensional teaching materials include paper teaching materials, audio and video products, electronic and network publications; And the video resources are one of the traditional work in the development of education technology; compared with other forms of media, video has certain dissemination characteristics in space and time, showing an outstanding education advantage, as a pre-project of "Quality Engineering" - excellent courses have started in 2003, when it referred to the excellent courses with distinctive features and outstanding teaching level. Due to the limitation of video technology and the network bandwidth, the number of video offered in the courses was limited, the quality was not high, and the design was not reasonable. After several years of development, the video resource project has progressively developed into the National Micro Teaching in universities and colleges, the university occupational development and employment guidance courses selection, in China brand courses selection, the old scientist academic growth projects, important positions, application, response and conclusion of the projects, the collaborative innovation between different schools and in-school.

The research and development of the teaching materials based on various electronic media forms materials not only makes the contemporary course resources develop from the single paper teaching materials in the past into text electronic teaching materials, electronic teaching materials and multimedia network teaching materials and other threedimensional teaching resources solutions, which will also drive the transformation and development of course and teaching models.

\section{REFERENCES:}

[1] Xiao Wu. Construction of Online Courseware Base, Development of Three-dimensional Teaching Materials [ J] . Information on Publication. 2001, (24) .

[2] Tang Shengping. Brief Discussion on Development Thoughts of Three-dimensional Teaching Materials in Network Era [ J]. China Publishing Journal 2004, (4) 